\title{
Recurrent Breast Cancer with Metastatic Brachial Plexopathy
}

\author{
Takashi Irioka $^{1}$ and Hidehiro Mizusawa ${ }^{2}$
}

Key words: brachial plexopathy, breast cancer, FDG-PET $\left(2-\left[{ }^{18} \mathrm{~F}\right]\right.$-fluoro-2-deoxy-D-glucose-positron emission tomography)

(Inter Med 49: 1257, 2010)

(DOI: 10.2169/internalmedicine.49.3582)
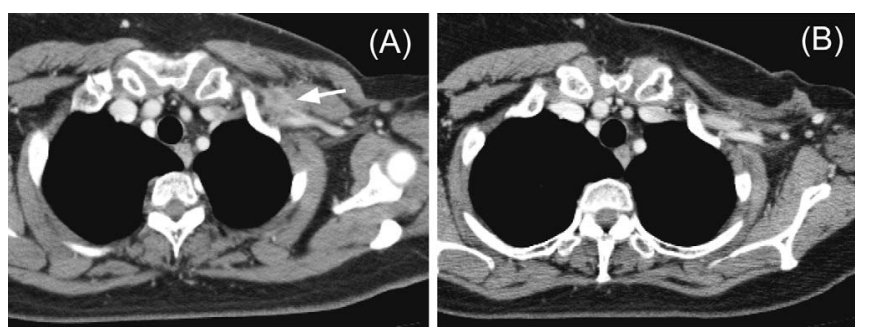

Picture 1.

A 59-year-old woman, with a past history of mastectomy for left breast cancer, was treated with chemotherapy for metastasis in the liver, lung, and left apical group of subclavian axillary lymph nodes; metastasis was revealed on enhanced computed tomography (CT) (arrow in Picture 1A). Two years after chemotherapy, she presented with sensory loss, pain, muscle weakness, decreased tendon reflexes, and edema in the left upper limb. Although follow-up CT disclosed no recurrent lesion (Picture 1B), 2- $\left[{ }^{18} \mathrm{~F}\right]-$ fluoro-2deoxy-D-glucose-positron emission tomography (FDG-PET) revealed abnormal uptake of FDG in the left subclavian axillary lymph nodes (arrow in Picture 2) and the left brachial plexus (arrowhead in Picture 2). The recent advances of FDG-PET in the diagnosis of breast cancer (1) and brachial plexopathy (2) resulted in the clear demonstration of cancer recurrence and its direct neural invasion in this patient.

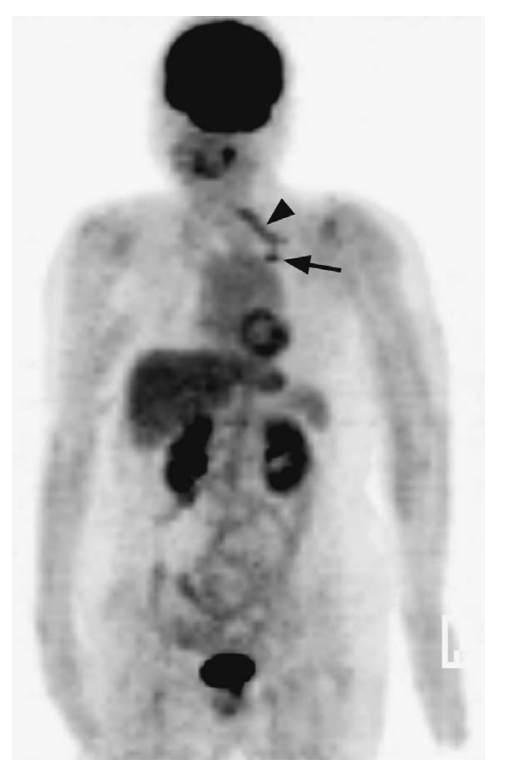

Picture 2.

\section{References}

1. Almubarak M, Osman S, Marano G, Abraham J. Role of positronemission tomography scan in the diagnosis and management of breast cancer. Oncology 23: 255-261, 2009.

2. Ahmad A, Barrington S, Maisey M, Rubens RD. Use of positron emission tomography in evaluation of brachial plexopathy in breast cancer patients. Br J Cancer 79: 478-482, 1999.

\footnotetext{
${ }^{1}$ Department of Neurology, Yokosuka Kyosai Hospital, Kanagawa and ${ }^{2}$ Department of Neurology and Neurological Science, Graduate School, Tokyo Medical and Dental University, Tokyo

Received for publication February 24, 2010; Accepted for publication March 10, 2010

Correspondence to Dr. Takashi Irioka, t-irioka.neuro@ykh.gr.jp

(C) 2010 The Japanese Society of Internal Medicine Journal Website: http://www.naika.or.jp/imindex.html
} 